\title{
GREENE VARDIMAN BLACK (1836-I9I5), THE GRAND OLD MAN OF DENTISTRY
}

\author{
by \\ D. HENDERSON
}

THE study of modern dentistry must always be undertaken with a sensitive awareness of the chain of developments which have produced the science as it stands today. Reviewing the formative years of the dental profession, one cannot help being arrested by the massive contribution of one man. Few can have influenced the development of their professions so markedly as did G. V. Black in the latter half of the nineteenth century and the early years of the twentieth. It was indeed fortunate that a man of his calibre should have applied himself to dental research at such a critical stage of its history. To summarize his achievements in a sentence is impossible; the nearest possible generalization is to say that he established dentistry upon a scientific basis and raised it to truly professional status. Accordingly, he was recognized during his own lifetime as 'the father of scientific dentistry', and was soon to be called 'the grand old man of dentistry'. Dr. Henry W. Morgan described him as 'one of the mighty forces that was elevating dentistry to the standing of a learned profession'. ${ }^{1}$ True there were other 'mighty forces' operating alongside him-men like John Tomes, W. D. Miller, and Leon Williams-but somehow Black's contribution silhouettes prominently against even this distinguished background, mainly by virtue of his admirable researches in the field of operative dentistry and the treatment of dental caries. His pioneer work, however, extended in many other directions and still remains the foundation of much of our knowledge, being extensively reflected, both directly and indirectly, in current dental literature forty years after his death!

Greene Vardiman Black was born on 3 August $18{ }_{3} 6$, near Winchester, Scott County, Illinois. His father was a cabinet-maker and farmer, and the family had not long since left Tennessee to settle in Illinois. Thus he and his four brothers and one sister were brought up in the rough environment of a typical group of pioneer settlers during the period of disturbed American home politics prior to the Givil War. When he was about eight or nine the family moved to a farm in Cass County; he and his brothers helped their father to erect their new house. But the young Black did not seem to fit into his surroundings as did the rest of the family. It appears that he was a difficult child, quite unsuited to the life of the settlers, a square peg in a round hole. His brother Carl tells us that he had two pet aversions, 'he would not go to school and he was not interested in the work of the farm'. ${ }^{2}$ It appears that he attended the local school (built on the farm for the benefit of the few neighbouring children) for a total of only six or seven months over a period of several years; this 


\section{Greene Vardiman Black (1836-1915), the Grand Old Man of Dentistry}

comprised the whole of his formal education. His family, with the exception of his mother who had great faith in him, could not understand him and regarded the young Greene as something of a misfit.

Although he would not be taught, the young Black was apt to teach himself. A plaque erected to his memory in Northwestern University states that 'he roamed the woods with dog, rod and gun, and became intimately acquainted with every tree, animal and insect. He thus developed in nature's laboratory methods of clear thinking and logical deduction.' His powers of observation and of sound reasoning taught him more than the best schools teach most of their pupils over many years. His interest in natural history stayed with him throughout his life, deepening as he grew older; so also did many of the other pursuits of his childhood days. His family was very musical, and as the years passed Black mastered the flute, the violin, the 'cello, the double bass, the cornet, the piano and the church organ, all apparently without proper instruction yet all to a high standard of accomplishment. He had a fine tenor voice, and at twenty-five was the leading singer in a local Church choir.

Black's interest in nature inclined him to the study of medicine, which he began at the age of seventeen, working from 1835 to 1856 under his brother Thomas, who was then practising at Clayton, Illinois. But his early years had developed in him an innate mechanical facility, and in 1857 he turned his attention to dentistry, studying under Dr. J. C. Spears, near Mount Stirling, Illinois. Bunting attributes this change to Black's eager desire to get married, an ambition likely to be expedited with the greater financial rewards then associated with dental practice. After a year with Dr. Spears, a man who had a profound influence upon Black in many ways, he opened his first dental practice in Winchester, Illinois; but the political sky was speedily darkening, and soon the storm broke and the American Givil War started. In 1862 he abandoned his practice to enlist in the 129th Illinois volunteers, but was discharged in the following year, having spent six months in hospital recovering from war wounds.

From 1864 to 1897 Dr. Black practised dentistry at Jacksonville, and it was in his office there that the earlier part of his researches was performed. Rapidly his fame spread beyond the boundaries of the small town, and his untiring efforts soon made the Jacksonville office renowned in American dental circles. Prominent men visited him to meet and discourse with him. Dr. Thomas Gilmer, in a speech delivered at a banquet in Black's honour in 1910, tells us that he opened a practice in $187 \mathrm{r}$ in the vicinity of Jacksonville.

It was not long [he says] before I came into contact with Dr. Black's patients. I saw the beautiful fillings he had made. I saw beautiful restorations; I saw beautifully contoured fillings, artistically finished, perfectly polished, and I also saw exemplified in the mouths of his patients even at that early day that which has since become a byword the world over-'extension for prevention'.s

Dr. Gilmer resolved to visit this great craftsman, with whose fame he was already acquainted, but was somewhat nervous at the prospect of such an interview. He had conceived a picture of awe-inspiring austerity, a veritable giant in 


\section{Henderson}

whose company he would feel ill at ease. At last, however, he plucked up courage to make the visit, and he described his experience in these words:

I was wondering what I would say; when I saw Dr. Black I knew I would make a fool of myself. Presently a gentleman walked in ... he greeted me with a smile on his face, a twinkle in his eye, and a warm handshake. He said, 'I am glad that you came to see me. I have wanted to see you ever since you located in Waverly.' From an insignificant boy, and a dwarf at that, I had developed into a full-fledged man immediately. I was nervous no longer; I had no more tachycardia, in fact I was made somewhat chesty to be received in such a way by such a man. When the patient left the office, he invited me into his operating room. He showed me his instruments, how he prepared blocks of gold for filling teeth, etc.

Then he said, 'Let's go upstairs', so we went to the third floor. There I saw all sorts of things, a big foot-turning lathe, fine tools of all kinds, an anvil and things that go with it, mechanical drawings on the walls, some moving clockwork causing a fluid to flow slowly over some teeth suspended in a jar, which I afterwards learned was an effort to produce chemical erosion of the teeth. I also saw test tubes and other chemical apparatus, and a blackboard with chemical symbols on it. He was teaching chemistry to a class in this room those days. There were gas bags and other things too numerous to mention. I gazed at all these things in wonder.'?

Later, Black moved his office to his private house in another part of the town, but it may be supposed that both his geniality and his paraphernalia accompanied him. Early in the Jacksonville period of his life he started the chemistry classes of which Dr. Gilmer saw evidence, and he did so because he was quite ignorant of the principles of this basic science and desired to learn. Throughout his life Black implemented his firm conviction that the best way to learn is to teach. His early studies in the basic sciences, especially chemistry and physics, led to his first important research work on gold foil. At this time the use of gold foil as a filling material was fairly general, Robert Arthur having described a method for making gold leaf cohesive in $1835 .{ }^{4}$ But it was a widespread experience amongst dentists that they were unable to preserve the cohesive properties of the material after exposing it to the atmosphere for any length of time. Realizing that the effect of the atmosphere must be that of its component gases, Black experimented to determine the effect of different gases upon the cohesive property of gold foil. He found that all elementary gases have a neutral effect, with the exception of chlorine which is harmful; that some gases, notably those containing phosphorus or sulphur are more detrimental than others, permanently destroying the cohesive property; and that ammoniacal gases are exceedingly beneficial after re-annealing the gold. Sulphurous acid gas, phosphoric acid gas and sulphuretted hydrogen were found to be particularly harmful, more so on annealed than unannealed gold. These facts Black explained as an expression of the volatility of the compounds produced by condensation of gases on the surface of the foil, non-volatile compounds permanently destroying the cohesive properties, excess ammonia neutralizing all the harmful substances condensed on the surface and itself being readily volatilized by re-annealing. Thus he had solved the problem of preserving gold in a cohesive state. 'A small amount of ammonia set in the gold drawer loosely corked, will be found sufficient to protect our gold from all harm. ${ }^{5}$ The real 


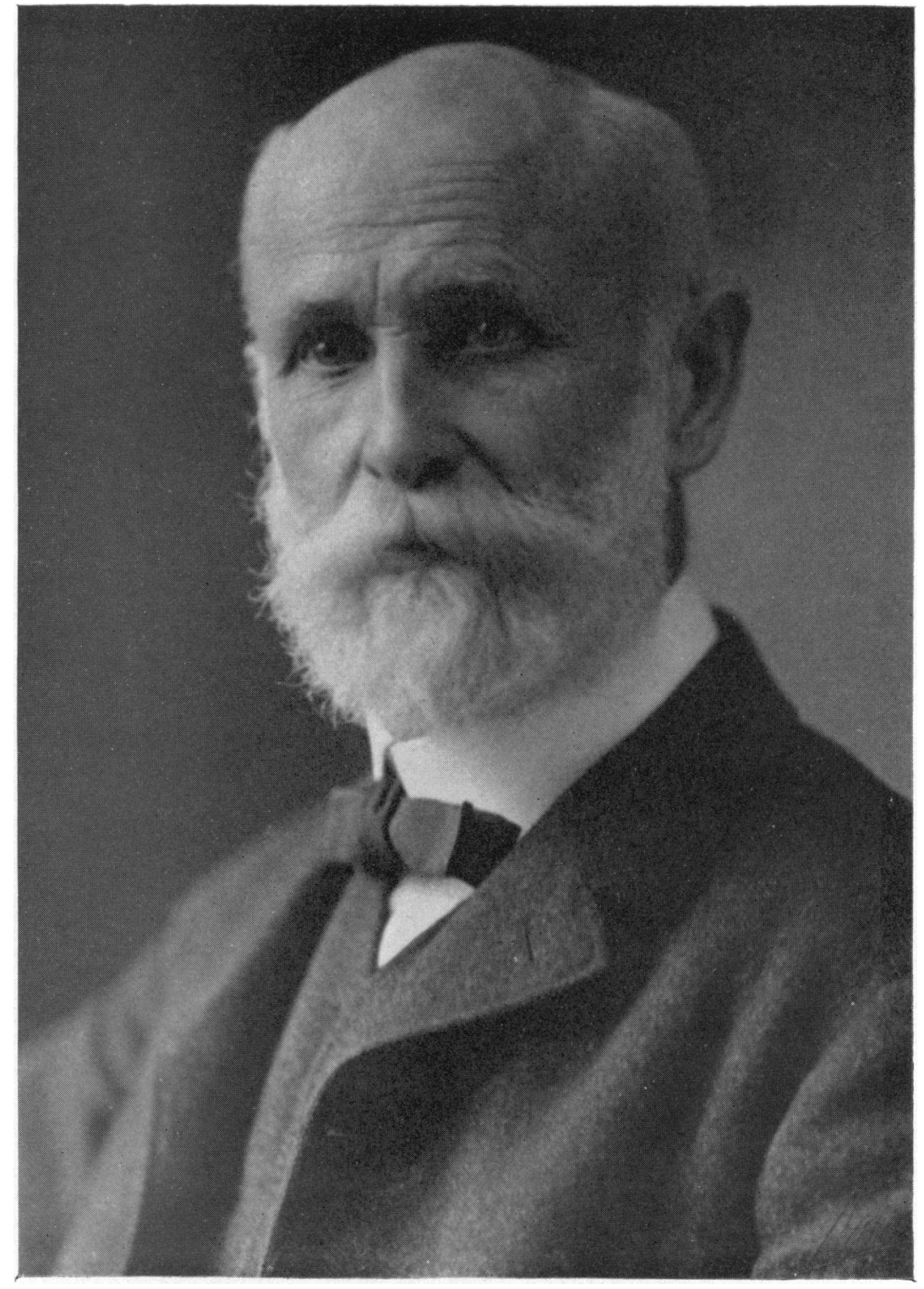

Fig. I

Greene Vardiman Black (i836-igi5) 


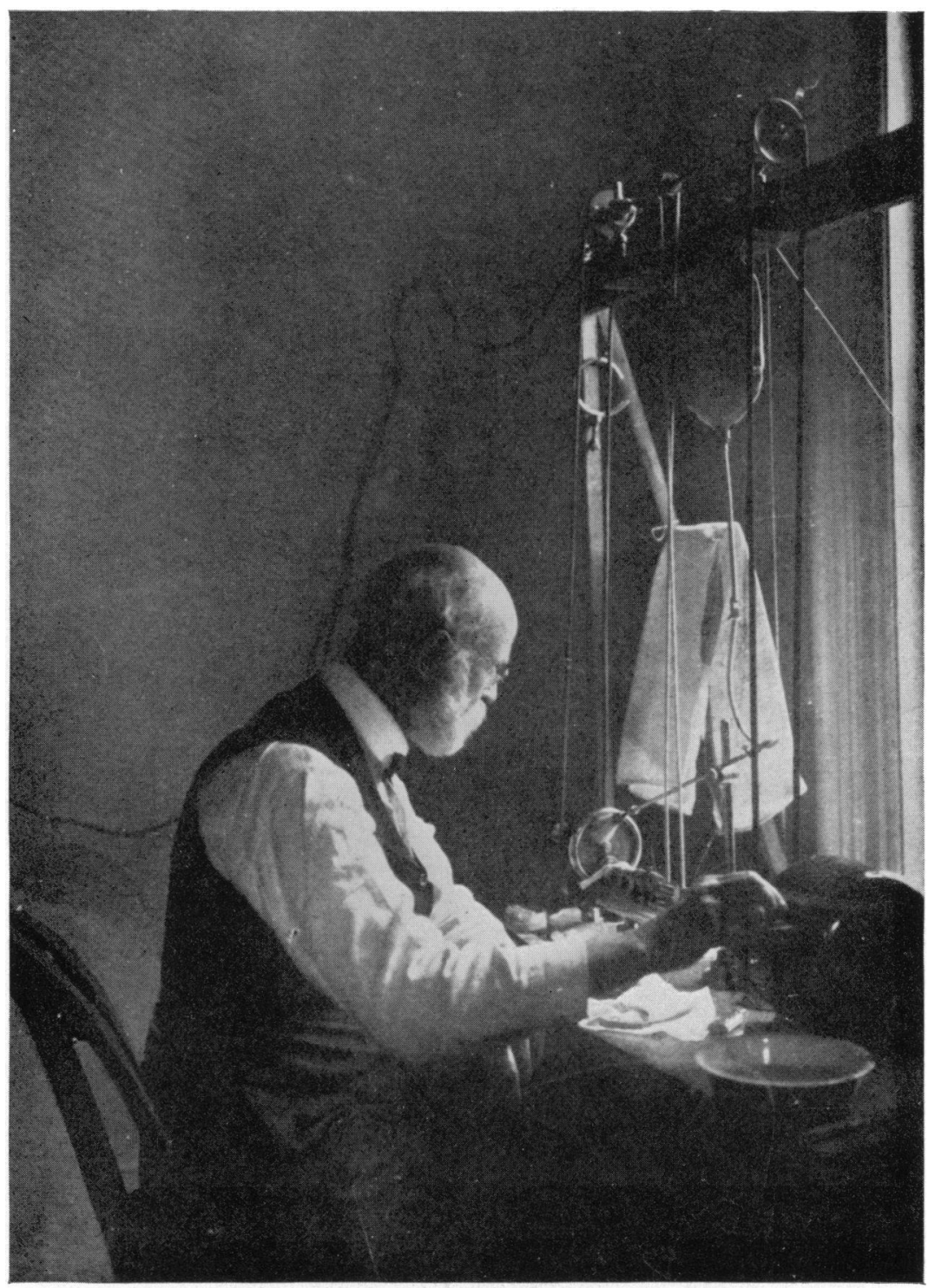

Fig. 2.

Greene Vardiman Black in his laboratory 


\section{Greene Vardiman Black (1836-1915), the Grand Old Man of Dentistry}

significance of the study, however, lies in its display of the chemical properties of contamination. This work has become a classic; the conclusions were first incorporated in a paper read before the Illinois State Dental Society (of which Black was president from 1870 to 1871 ) in the year 1869 , and later published in the Missouri Dental Fournal of that year.

A short time before Dr. Black opened his first practice the cell theory had been formulated, and with the aid of a microscope he began the pursuit of histology. 'He studied cells and tissues, dissected earthworms and insects and everything he could get hold of until he became a proficient microscopist.' Dr. Fred Noyes reports that 'many of the physicians of Jacksonville had fallen into the habit of sending specimens to him for microscopic examination'. 6 He relates one rather amusing incident in this connexion.

One day, as he (Black) was operating at the chair, the door opened and a physician who gave special attention to the eyes said, 'Here's something that I took out of a man's eye. I wish you would examine it and tell me what it is.' He put the vial on the desk. A few days later, the same man stuck his head in the door and asked-'Well, did you find out what that was?' Without looking up from his operation, Dr. Black replied, 'Yes, that was the first joint of the third leg of a potato bug!'

Reference has already been made to the enthusiasm with which 'G. V.' sought to teach others. Not only did he deem this a sound way of thoroughly acquainting himself with his subject, but also he had a passionate desire to communicate any knowledge that he acquired. So great was this inner compulsion that he made frequent visits to the Missouri Dental College to lecture in pathology, histology and operative dentistry (a lectureship he held from 1870 to I880), involving a journey of some Ioo miles from Jacksonville. The first twenty-five miles were covered on horseback, and the remainder by boat down the Illinois river to the Mississippi, and on to St. Louis where the College was situated. After a few days teaching he would return by the same route. In I87 I the College awarded him the honorary degree of Doctor of Dental Surgery. There follows a long list of his appointments and accomplishments. He was the first president of the Illinois State Board of Dental Examiners from its inception in I881 until 1887. In 1883 he was appointed to the Chair in Dental Pathology at the Chicago College of Dental Surgery, a position he held for six years. During this time, and at the age of 48 , he published his first book, which was a pioneer study of the oral bacteria entitled The Formation of Poisons by Microorganisms (1884). This was followed in 1887 by The Periosteum and Peridental Membrane embracing a field to which Black devoted a great deal of work, with particular reference to histology. He was asked to write chapters on 'General Pathology', 'Dental Caries', 'The Pathology of the Dental Pulp 'and on 'Diseases of the Peridental Membrane' in the important American System of Dentistry, published in I886. From I89o until 1891 Black was Professor of Dental Pathology and Bacteriology in the University of Iowa. During this time, two very important works issued from his pen. Firstly, in I891, the classic Descriptive Anatomy of the Human Teeth was published, being the first serious attempt to 


\section{Henderson}

describe the anatomy of the teeth ever written, and still a leading reference on the subject. Secondly, in the same year, there appeared a series of five articles in the Dental Cosmos entitled 'The Management of Enamel Margins'. This last embodied Black's greatest contribution to the practice of dentistry, namely the principle of extension for prevention in cavity preparation, a concept to which his name will be immortally annexed. He defined cavity preparation as

such a mechanical treatment of the injuries to the teeth by dental caries as will best fit the remaining part of the tooth to receive a filling restoring the original form, give it strength, and prevent recurrence of decay in the same surface.

These papers concerned the exact delineation of the boundaries to which cavities should be cut to provide conditions most favourable for the permanence of the finished restorations. Repeatedly during his life he emphasized that certain areas of a tooth's surface are susceptible to caries whilst other areas are immune. He produced various charts of caries incidence in different surfaces of the teeth, and from studies of this kind was able to specify the relative immunity of the different tooth surfaces; knowing this enabled him to delineate the proper position for the margins of his restorations, according to his conception of preventive extension. This principle he defined as 'Removal of the enamel margins by cutting from a point of greater liability to a point of lesser liability to recurrence of caries' ${ }^{8}$ At proximal surfaces this means 'to cut enamel margins from lines that are not self-cleansing to lines that are self-cleansing, especially away from the contact areas'. Black's argument was developed in a masterly way, being based on the histology of enamel and the development of the tooth. He summarized his work thus:

1. Cut the enamel to such a point that the surface of the filling may be so formed that the enamel margin will be self-cleansing, or be protected by the gum margin.

2. Do not form an enamel margin in such a position as to leave a small portion between it and one of the developmental grooves.

3. So form the immediate margin of the enamel that it will present no short ends of enamel rods on its outer surface without sloping it outward so much that the filling material will not have good edge strength.

From I891 until he left the Jacksonville practice Dr. Black was Professor of Dental Pathology and Bacteriology at Northwestern University Dental School. These eight years yielded further important contributions from his researches. Whilst chairing the section on Aetiology, Pathology and Bacteriology of the World's Columbian Dental Congress of 1893 , he delivered a report on dental nomenclature which has survived to the present day and is unlikely to be superseded. This extended to all descriptive dental anatomy, instrument nomenclature, cavity nomenclature and many other branches of the subject. Also in the year of the Congress he published a paper entitled 'Anchorage of Proximate Fillings in Bicuspids and Molars', published in the Dental Review. Perhaps the most significant contribution of this period was a further series of five articles which were published in the Dental Cosmos of 1895 entitled 'An

$$
136
$$




\section{Greene Vardiman Black (1836-1915), the Grand Old Man of Dentistry}

investigation of the physical characters of the human teeth in relation to practical dental operations, together with the physical characters of filling materials'.

This somewhat ponderous title is in keeping with the massive nature of the work, which set out to

determine the facts as to the differences in the physical properties of the teeth with reference to hardness and softness as represented by the percentage of calcium salts in the dentine and the relation this held to caries.'

His conclusions almost immediately evoked a storm of protest from the profession, being almost revolutionary and confuting the acknowledged postulates of the day. Indeed, Black admitted to his own astonishment at the results he obtained, but his work had been performed in an unassailably scientific manner and was in due course accepted by all.

His work established that there was a close similarity between the overall specific gravities of the dentine of teeth from I I I persons investigated, although there was a difference between the specific gravity of the teeth from the same person; that the specific gravity did not depend solely upon the weight of the lime salts contained in the specimen. He stated that free water averaged some I I per cent of the weight of the tooth (dentine block) and that the percentage of lime salts averaged approximately 6 I to 65 per cent over the entire selection (with the exception of one tooth). Hence this factor cannot be of much consequence in determining the 'hardness' or 'softness' of teeth if these qualities do in fact vary. He found that the organic constituents averaged 25.36 per cent and bears an inverse relation to the density. Black wrote

I have come to regard the organic matrix of the tooth as much more important than I had formerly considered it. The condition of the organic matter seems to have much to do with the strength of the tooth.

He found an increasing density and percentage of lime salts with increasing age, and noted a check in the rise of both characters between the ages of twenty and forty, equal in both sexes and therefore independent of the child-bearing period of women. He concluded that caries cannot be explained on the assumption that the teeth of susceptible persons differ in their physical characteristics from those of immune persons.

Abandoning himself to whole time research and teaching, Black accepted the Chair of Operative Dentistry at Northwestern University Dental School in 1897 leaving the Jacksonville Practice for good. In this capacity he worked until his death in I915. Much of his research during this period was founded upon the previous work performed at Jacksonville, and it is convenient to summarize the whole of the 'Northwestern University Period' as one, although it included the last eight years of the 'Jacksonville Period', and was largely derived from the experience of his whole life. Indeed, this division of Black's life had much to commend it, for the more academic years of Northwestern would have been impossible without the vast clinical experience gleaned whilst at Jacksonville. 


\section{Henderson}

Perhaps it is the symbol of what made Black succeed, that the practical background assured the theoretical propositions their lasting calibre, two distinct eras merging into each other over eight pregnant years. The following, then, is a list of his further achievements during this latter period:

I. He studied in detail the physical properties of amalgam. The results are scattered through many papers, and gathered together in the comprehensive book, which to this day remains his greatest memorial-Operative Dentistry. This last was published in two volumes in the year 1908 and in its modern editions maintains its position as a standard text-book today. When originally published it was considered to be very much in advance of its time and exceedingly controversial. One reviewer expressed this as follows:

These two volumes can hardly be classed as suitable for undergraduate students. They are rather the material from which a text book or text books could well be made. While there is a vast amount of matter which every dental college student should have at his fingers' ends there is an equal amount which is beyond his grasp and is suitable only for the mature mind of the trained thinker. ${ }^{10}$ (Dental Cosmos, 1908.)

2. He presented some significant advances in the study of dental calculus.

3. He repeated Miller's work on dental caries, found it good, and then carried the investigation a stage further, emphasizing the importance of the microbic plaque in the aetiology of dental caries.

4. This led to a final systematization of the basic theory of cavity preparation, which occupied his attention more than any other single subject. Black's work in this sphere is of paramount importance to the understanding of his contribution to contemporary dentistry.

His work with reference to cavity preparation may be divided into two sections. Firstly that relating to cavity design, and secondly that relating to the systematization of procedure in cutting the cavity. Concerning the latter his famous principles were first expressed as follows:

General Principles. There are certain fundamental principles that are general to the excavation of various cavities in the teeth, the observance of which will simplify and facilitate these operations which may be expressed as follows:

First, obtain the required outline form.

Second, obtain the required resistance form.

Third, obtain the required retention form.

Fourth, obtain the required convenience form.

Fifth, remove any remaining carious dentine.

Sixth, finish the enamel wall.

Seventh, make the toilet of the cavity.

In certain conditions the fifth of these should be placed as the second. These will be found to be exceptions to the general rule. ${ }^{11}$

He gave in great detail an outline of the proper application of these principles to almost every lesion likely to be encountered clinically.

The principles intended to control the development of the outline form of a cavity have already been mentioned. Certain further mechanical requirements 


\section{Greene Vardiman Black (1836-1915), the Grand Old Man of Dentistry}

are involved in the establishment of proper resistance and retention form. In 1893 Black published an article entitled 'Anchorage of Proximate Fillings in the Bicuspids and Molars'. Normally proximate restorations are composite and therefore exposed to the force of mastication through the occlusal components. (At a later date, he was to investigate the intensity of the maximum masticatory force, the tooth strength and the strength of the filling materials.) Black spoke of 'crushing strain' (this is the 'force of mastication brought directly upon the surface of the filling'), and 'tipping strain' (or, 'the result of any force brought in such a way as to pry a mesial filling to the mesial or a distal filling to the distal'). ${ }^{12}$ $\mathrm{He}$ described in detail the appropriate form of cavity and restoration needed to resist these forces. All these principles were adequately illustrated with examples.

The next important book written by Dr. Black appeared in 1915, entitled Special Dental Pathology, and this work is incorporated with Operative Dentistry in many modern editions. It deals at considerable length and in minute detail with the pathology of the investing structures of the teeth. Black's contribution to this branch of dental science was an important one, although more in terms of intermediate research than was the almost entirely original and absolute work on the treatment of caries. Finally, a series of papers entitled 'Mottled Teeth; an Endemic Developmental Imperfection of the enamel of the Teeth, heretofore unknown in the literature of Dentistry', was published in the Dental Cosmos a few months after his death. In this work he co-operated with F. S. McKay who has subsequently carried the subject of fluorine in relation to caries a good deal further. Black's detailed description of the histo-pathology of enamel affected in this way remains more or less accurate despite the great interest evoked by the condition, which has since received much attention. The articles describe the work of many years, which consisted of an examination of a group of people affected by the condition in a certain American locality.

In I910 the Chicago Odontographic Society gave a banquet in Black's honour. This great occasion must have been one of the highlights of his career; certainly the published speeches of the evening give us some conception of the high regard in which he was held by his contemporaries. Here we find stories and anecdotes which display Black the man, the human being; here we see just how his mind worked, just what sort of impression he made on his friends and associates. Here we get some idea of how he spent his leisure time, and indeed it appears that his recreational activities were almost as extensive as his vocational accomplishments. Of the latter, one speaker remarked:

Our honoured guest is one, who through a long and fortunate career has been able to render signal service to his profession, and through them to benefit mankind, and at the same time achieve a just and great renown for himself. ${ }^{13}$

Nevertheless, Black's remarkable endeavours embraced more than one field of activity. He was by no means a man of one subject. He took an intense and detailed interest in all that surrounded him. From another speech we learn that:

He observed the clouds, the trees, the fauna; whether he is in the woods or fishing he can always tell you something interesting about commonplace things. He seems to have studied well-nigh 


\section{Henderson}

everything, embryology, bacteriology, meteorology, histology, pathology, minerology, metallurgy, zoology, etc. ${ }^{14}$

He loved hunting and fishing. Throughout the whole of his life at Jacksonville he never once missed one of the twice-weekly evening meetings of the local literary society when he was in town. Indeed it was his habit to read every one of his scientific papers to a lay friend from this society; and should the language prove to veil his meaning from this friend he re-wrote the section until it was readily intelligible to his non-scientific companion. This accounts for the extraordinary clarity of his written work, which is markedly lacking in any ambiguity of any kind, and is almost childishly simple in its style.

Black was an expert draughtsman; he loved to paint pictures, and nearly all his papers were illustrated from his own pen. The detail of his work is clearly reflected in the minuteness of his illustrative technique. We have already spoken of his musical accomplishments and hinted at his linguistic abilities, the latter exemplified in his mastery of several foreign languages, including French and German, to a degree which enabled him to present papers in these tongues as well as in English. Early on he designed and built his own sailing boat in which he spent many weeks sailing on the American rivers and lakes. All this was achieved in addition to the phenomenal output of literature from his pen. $\mathrm{He}$ wrote on many subjects unconnected with dentistry, ranging from sewage problems to the re-organization of the police force.

His work required the very utmost of accuracy in measurement and frequently suitable instruments were not available. Consequently he designed and made many of his own instruments, one of which was a pioneer foot-driven dental engine. This last was one of the first ever patented and takes a significant place in the evolution of modern engines. His dynamometers, modified for several different purposes, included a gnathodynamometer for measuring masticatory forces, and a phagodynamometer to measure the forces involved in disintegrating normal foodstuffs.

He invented an electric thermostat, a micrometer for measuring amalgam expansion which was exceedingly delicate, a machine for grinding sections of teeth, and a microtome, to mention but a few. These he appears to have been able to construct to a finer degree of accuracy than were the official instrument makers of his day-an ability which must make any dentist envious in these days of company monopolies. But one comment made of Black in the rgro speeches stands out as the most delightful of all; and it is a sentiment which many of his friends appear to have echoed at some time or another. 'He was kind, generous, lovable and in all ways good.' It is rarely that a man of such indisputable genius has impressed his friends in this way.

\section{Conclusion}

It only remains to attempt some kind of assessment of Black's influence upon the evolution of modern dentistry. The following four standards for this assessment are suggested: 


\section{Greene Vardiman Black (1836-1915), the Grand Old Man of Dentistry}

(I) That of absolute achievement; or the answer to the question, 'How much of his work still stands absolutely true, accepted by his successors, verified by subsequent investigators?'

(2) That of relative achievement; or the answer to the question, 'How much of his work has provided an indispensable link in the chain of discovery? How much subsequent work would have been impossible in the absence of his as a basis?'

(3) That of negative achievement; or the answer to the question, 'How many unfounded notions and unsound theories has he conclusively refuted?'

(4) That of personal influence.

I. Absolute Achievement. We have seen that Black established certain facts, principles and methods of procedure which have stood the test of time without material modification. These were:

(i) He systematized the operative treatment of dental caries, according to certain principles of cavity preparation. Of these, the most important were, $(a)$ the preventative extension of cavity margins, $(b)$ a seven-stage operative sequence, $(c)$ principles of design for mechanical stability and permanence of function, and $(d)$ the application of these principles to the peculiarities of structure associated with different teeth.

(ii) He devised a system of descriptive dental nomenclature including, (a) a classification of cavities for purposes of treatment, $(b)$ appropriate descriptive terms for application to all parts of the teeth and of cavities in the teeth, and $(c)$ a classification of dental instruments. All these have been universally accepted and adopted by the profession.

(iii) He produced a classification of points at which incipient caries may be located, which has since become the basis of modern diagnostic procedures.

(iv) He established that the chemical constitution and physical characteristics of teeth are not the determining factor in their susceptibility or immunity to caries.

(v) He wrote the first text-book of human dental anatomy. The excellence of this work and the thoroughness of its execution have made Black's Descriptive Anatomy of the Human Teeth the finest book of its kind ever written.

(vi) He discovered a method of maintaining the cohesive properties of gold foil, and described the physico-chemical principles of its contamination.

2. Relative Achievement. It is instructive to note the tremendous impetus given to the development of dentistry during the closing decades of the last century, and to compare it with the slow progress of the previous years. Whereas it is largely connected with similar advances in allied medical and scientific fields, this impetus was imparted in no mean measure by the pioneer work of men like Black and his associates. We may, perhaps, summarize Black's influence in this way as follows:

(i) His early bacteriological studies stimulated interest in dental bacteriology and greatly advanced its study. Black was responsible for several laboratory techniques which were indisputably a part of the evolution of our modern 


\section{Henderson}

methods. This interest in turn led to the wider appreciation by the profession at large of the importance of the work of Miller on the aetiology of caries.

(ii) Along with Miller and Williams, Black contributed enormously to our present conception of the aetiology of dental caries. His most important work in this field was to draw attention to the importance of bacterial plaques in initiation of the carious process. Also he directed attention to the hereditary factor.

(iii) His work on the physical and chemical properties of amalgam has proved to be of great importance in the evolution of modern dental amalgams and proper methods of manipulating them.

3. Negative Achievement. In one sense each of Black's positive discoveries caused some valueless and harmful theory to be abandoned. Indeed, we could justly include in this section the converse of most of the things we have already mentioned; however, there are three matters which must be emphasized.

(i) Black disproved the common notion that the chemical and physical structure of the teeth is an important predisposing cause of caries. This discovery was of revolutionary significance as may be readily ascertained from the literature of the time.

(ii) He disproved the notion that the teeth of women are weakened, or made more liable to caries in themselves, by the supposed withdrawal of lime salts during the child-bearing period, especially during pregnancy.

(iii) He was significantly associated with the final rejection of the inflammatory theory of caries; even though he appeared on the scene rather late in the day, nevertheless his gift for teaching was one of the most important factors in the quick dissemination of the acidogenic theory, and therefore in the final displacement of its predecessor.

4. Influence. In his personal influence we encounter one of Black's most significant contributions to the development of dentistry. Constantly in the literature we may read of those who paid tribute to the impact made upon them by G. V. Black, and amongst them the names of those who have added much to our knowledge. For example, Dr. Leon Williams recorded that, but for the influence of Black, he would have been more than discouraged during his early days as a research worker. In some sense, then, we may never have had the benefit of Williams' work had it not been for Black. There are many examples of the same kind, frequently to be encountered in the records of dental society meetings in Illinois State and elsewhere. Only his contemporaries can adequately express this kind of thing, for they are the ones who met him in person. Let us then listen to Dr. William A. Evans, speaking of the booklet of Black's writings at the banquet in 1910 . He said:

I believe that one can legitimately count as the writings of the man not only the things which he has written by his own hand, but also the things that his inspiration has served to have written by the hands of other men. And so this book of thirty-five pages is but a small part of the great procession of pages in which is set forth dental research and the advances of medicine and the advances of science-a procession of pages that reaches to every part of 


\section{Greene Vardiman Black (1836-1915), the Grand Old Man of Dentistry}

the civilized world-pages that cannot be counted by the tens or by the hundreds, or by the thousands. And not only that, but they leave the imprint of a genius and his influence upon every scientific page that has been written in the last quarter of a century in the civilized world'.15 (1910)

What more is there to say? We have studied the work and influence of one who was, in the words of Dr. Lilian Lindsay, 'One of the really great names in dentistry belonging to modern dentistry more than any of his predecessors.' ${ }^{16}$ Earlier we said that his greatest memorial is the book called Operative Dentistry; but is there not a greater memorial than this? Surely Greene Vardiman Black's greatest memorial is the modern practice of Operative Dentistry?

\section{REFERENCES}

I. Morgan, H. W. (19ro). Dent. Rev., xxiv, 267.

2. Black, G. E. (1936). Northw. Univ. dent. Res. Bull., xxxvi, No. 47.

3. Gilime R, T. L. (1910), Dent. Rev., Xxiv, 222.

4. Arthur, Robert (1835). Dental Newsletter, vim, 129.

5. Brack, G. V. (1869). Gold Foil, Missouri dent. F., I, 283.

6. BlackWell, R. E. (1936). Northw. Univ. dent. Res. Bull., xxxv1, No. 47.

7. Black, G. V. (1908). Operative Dentistry, In, 105.

8. Bracx, G. V. (1891). Dent. Cosmos, xxxm, I.

9. Brack, G. V. (1895). Dent. Cosmos, xxxuIn, 353, 469, 553, 637, 737.

10. Dent. Cosmos. (1908). $\mathrm{L}, 1281$.

II. Black, G. V. (1908). Operative Dentistry, II, 110.

12. BlACK, G. V. (1893). 'Anchorage of proximate fillings in the bicuspids and molars', Dent. Rev., vII, 429.

13. Logan, W. H. G. (1910). Dent. Rev., Xxiv, 220.

14. Gilmer, T. L. (1910). Dent. Rev., Xxiv, 234.

15. Evans, W. A. (1910). Dent. Rev., Xxiv, 246.

16. Lindsay, Lilian (1933). A Short History of Dentistry. London, J. Ball, Sons and Danielson Ltd.

GENERAL

Black, G. E. (1936). 'Greene Vardiman Black: his aptitudes', Northw. Univ. dent. Res. Bull., xxxvi, No. 47.

Black, G. V. (1908). Operative Dentistry, I and In, Chicago Medico-dental Pub. Co.

BlackWell, R. E. (1936). 'Greene Vardiman Black-dean and teacher', Northw. Univ. dent. Res. Bull., xxxvi, No. 37.

Bunting, R. W. (1953). The Story of Dental Caries, Michigan, Overbeck Co.

Prinz, H. (1945). Dental Chronology, London, H. Kimpton.

Thовpe, B. L. (1910). History of Dental Surgery, edited by C. R. E. Koch, III, 570-80. Chio. Nat. Art. Pub. Co.

7. Allied dent. Socs. (1915), x, 409 .

Dent. Rev. (1910), xxiv, 219.

F. Nat. dent. Ass., Huntingdon, Ind. (1915). 